\title{
Three Rows Micro-piles in Debris Landslide Anti-sliding Mechanism Model Test Research
}

\author{
Qiang CAI ${ }^{1,2, a^{*}}$, Ji-Ming $\mathrm{KONG}^{3, \mathrm{~b}}$, Sheng-Wei SHI $\mathrm{SI}^{1,2, \mathrm{c}}$ \\ ${ }^{1}$ Technical Center for Geological Hazard Prevention and Control, CGS, Chengdu 611734, Sichuan, \\ China \\ ${ }^{2}$ Institute of Exploration Technology, Chinese Academy Geological Sciences, Chengdu 611734, \\ Sichuan, China
}

${ }^{3}$ Key Laboratory of Mountain Hazards and Surface Process, Chinese Academy of Science/Institute of Mountain Hazards and Environment, Chinese Academy of Science, Chengdu 610041, China

$a^{*}$ cq863@163.com, bimingk@imde.ac.cn, ${ }^{c} 250608289 @ q q . c o m$

${ }^{*}$ Corresponding author

Keywords: Micro-pile, Debris Landslide, Landslide Thrust, Soil Arching, Landslide Thrust Transfer Coefficient.

\begin{abstract}
Micro-piles are widely used because of its own advantages, but relatively few theoretical studies about its anti-slide mechanism. Through the different pile spacing under three rows of micro pile reinforcement debris landslide indoor model experiment to study the micro-piles against sliding mechanism. The test results show that: the pile spacing of $5 \mathrm{D}$, three rows of micro piles structure can produce sliding resistance of the biggest and the maximum sliding resistance. Pile been pressure and the bending moment of the piles mainly concentrated distribution within the scope of the sliding surface above $1 / 3$ pile range and closer to the surface greater. Landslide thrust transfer coefficient $\varsigma$ and $\xi$ respectively in $(0.54,0.71)$ and $(0.27,0.49)$ between the value.
\end{abstract}

\section{Introduction}

In recent years, research and control of landslide hazard is more active than ever, the further expansion and deepening of the research, prevention and control engineering measures also improve the existing measures on the basis of light, miniaturization direction. Micro-piles as a new type of anti-slide structure, due to its advantages in solving complex foundation and slope stability problems, landslide prevention and control at home and abroad, retaining structures, slope support (deep excavation protection, railway embankment) skid engineering applications, and achieved good project results and economic benefits. Due to the application of micro-piles relatively short history, the people in the prevention and treatment of landslide Bearing Mechanism, the form of force and failure mode and other issues also do not have a full understanding, there is no mature computing theory. For micro piles against sliding mechanism of theoretical research is relatively small, a comprehensive literature review, collection, analysis, processing on the basis of existing data accumulation, comparative analysis of existing research results at home and abroad the advantages and disadvantages of this paper to three rows of micro-pile physical model test for the study, reinforced by a single row of micro-pile debris landslide, different pile spacing under the working principle of micro-pile reinforced slope, the main research by force characteristics of micro-piles and soil.

\section{Physical Model Test Design}

\section{Test Purpose and Content}

Using model test, the three rows micro-piles reinforced gravel soil landslide model test of the process in which, repeat the process and characteristics of anti-sliding. Record different pile spacing single row 
under the strain of micro-piles and landslides in different parts of the stress on, and analysis of micro-piles and soil force distribution law.

\section{Model Material}

(1) Model pile

The model pile perfusion by a PVC tube made of cement mortar, wherein the cross-sectional size of the PVC pipe diameter $\mathrm{D}=2 \mathrm{~cm}$, length $0.6 \mathrm{~m}$, cement numeral $325 \#$, aggregate used is quartz sand with a particle diameter of $1.0 \mathrm{~mm}$.

(2) Slip material

Select the cement, quartz sand, silty clay and water can be configured to a variety of materials mass percentage ratio and mechanical parameters of the test material are shown in Table 1,2.

Tab.1 Mixture Ratios of Rock and Soil Materials

\begin{tabular}{ccccc}
\hline Material & cement $(\%)$ & quartz sand $(\%)$ & silty clay $(\%)$ & water $(\%)$ \\
\hline content & 2.0 & 60.0 & 32.0 & 6.0 \\
\hline
\end{tabular}

Tab.2 Mechanical Parameters of the Test Material

\begin{tabular}{ccccccc}
\hline density $\left(\mathrm{g} / \mathrm{cm}^{3}\right)$ & $\begin{array}{c}\text { quality of water content } \\
(\%)\end{array}$ & $\begin{array}{c}\text { proportion } \\
\left(\mathrm{g} / \mathrm{cm}^{3}\right)\end{array}$ & void ratio & \multicolumn{2}{c}{ direct shear trength } \\
\cline { 5 - 7 } content & 2.0 & 60.0 & 32.0 & $\mathrm{c}(\mathrm{kpa})$ & $\Phi\left(^{\circ}\right)$ \\
\hline
\end{tabular}

(3) Slide bed

In order to achieve the purpose of the stability of the landslide, the slide bed with a thickness of $0.07 \mathrm{~m}$ loess layer simulation.

\section{Three-rows Pile Model}

The test is divided into three groups, each group of ten model piles, pile spacing for $4 \mathrm{D}, 5 \mathrm{D}, 6 \mathrm{D}$, prepared as shown in Figure 1.

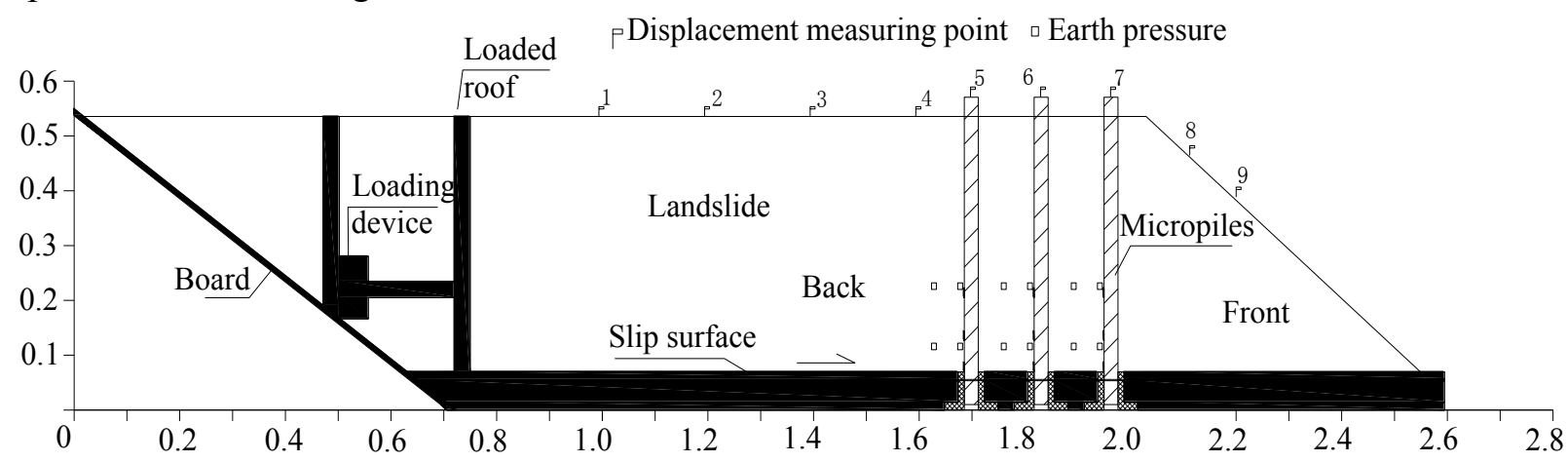

Fig.1 Test Model Diagram

\section{Test System}

The test system consists of monitoring components, strain-chip and data acquisition system. Including soil pressure gauge, digital strain gauges, displacement measuring instrument.

\section{Loading Design}

Landslide sliding landslide thrust has always been a stabilizing effect on the anti-slide pile for the simulation of this process, with the model test range of $20 \mathrm{kN}$ thrust loading device on the model pile been applied loads, to simulate micro-pile the landslide thrust load stage loading, the loading rate for each of the sliding body to the leading edge of the landslide mobile $10 \mathrm{~mm}$ slip displacement $S$. In each stage of 
loading applied to hold the charge for a certain time to pile structure stabilized before applied force and deformation under a load.

\section{Analysis of Test Results}

\section{Different Pile Spacing Pile under the Soil behind the Pressure Distribution}

Tested according to the test results, different slip displacement and pile spacing, slippery surface 4,15 $\mathrm{cm}$ at pile been pressure distribution pattern shown in Figure 2.

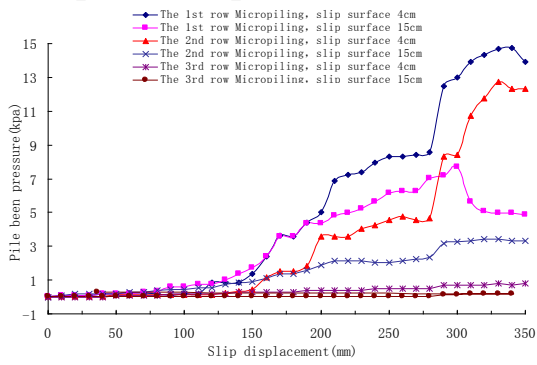

(a) Pile spacing 4D

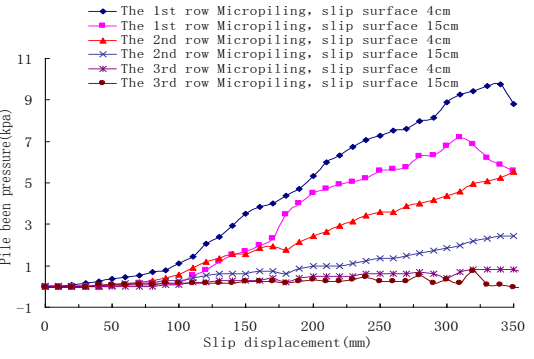

(b) Pile spacing 5D

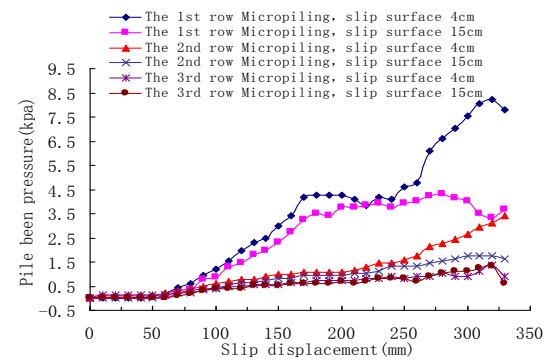

(c) Pile spacing 6D

Fig.2 Continued to Slide under the Conditions of the Pile Soil Pressure Distribution Curve

After loading, because the trailing edge of landslide soil in the instantaneous deformation stage, each row of piles embedded in the surface of the soil pressure meter basically no measured value of the effective stress. With the sustained growth of compression deformation of landslide body, after the first and second row pile and the soil arch effect between pile from top to bottom gradually enhance, through the soil arch is passed on to the first and second row pile pressure increases gradually, and the more the faster growth near the sliding surface of the earth pressure. Due to the thrust basically assumed by the first and two rows of piles, and the third row pile been pressure basic remain unchanged. Subsequently, soil arching between piles is destroyed, the first row of piles into the plastic stage, been pressure curve appeared inflection point, soil pressure surge, and soon the first row pile soil pressure peak, micro pile failure, pile soil pressure decreases rapidly, second rows of piles of earth pressure is growing rapidly, through the third row pile been arch is passed on to the pile pressure presents the obvious growth trend.

Pile spacing of 4D, when $S \leq 100 \mathrm{~mm}$, pile been pressure of zero. When $S=150 \mathrm{~mm}$, in the first row pile been pressure curve appeared inflection point, the soil arching. With continuous sliding of the sliding body, will not be stable because the micro pile soil stress transmitted to the stability of soil body, carries on the stress redistribution, the first and second row pile soil pressure dynamic growth. When $S>280 \mathrm{~mm}$, the first row pile into the elastic-plastic stress stage, the soil arch destroyed, the soil pressure peak, anti slide pile body failure. During loading, delivery to the third rows of small thrust on piles, the pile been pressure growth is not obvious.

Pile spacing of 5D, along with the continuous slippage of the sliding body, been arch is passed on to the first row pile by pile thrust increase gradually, the pile pressure increase by a wide margin, and been curve slope is basically the same. When $S>260 \mathrm{~mm}$, elastic stress limit of the first pile pile been pressure soon peak, the first row of pile failure, gradually withdraw from the anti sliding state. Second row piles take the main landslide thrust, pile been pressure increases rapidly and is passed on to the third row pile thrust increase, but did not cause the deformation of the pile is obvious pile been less pressure.

Pile spacing of $6 \mathrm{D}$, when $S \leq 70 \mathrm{~mm}$, main dissipation due to thrust in the process of sliding position shift, thus each row pile been pressure on the basic of 0 . With the increase of the horizontal thrust, been pressure of the first row pile increase greatly, as the pile spacing increases, pile of constraint function is reduced, part from the pile to pile before the slippage between soil pressure curve, the emergence of a fluctuating stage. Then the first row pile soil pressure curve inflection point, the pile into the elastic-plastic stress stage, pile soil pressure increases rapidly. The first row by row pile between piles on the transfer to the second row thrust increase, soil pressure curve inflection point. When $S=320 \mathrm{~mm}$, the first row pile yield failure, second rows of piles soil pressure rapid growth, the third row pile been pressure curve slope. 


\section{Different Pile Spacing Bending Moment Distribution Law}

Assuming that the micro-pile is always in elastic session, according to the calibration test is a model pile elastic modulus and strain values measured by the strain gages pasted along the pile by Formula 1 may calculate the corresponding measuring point bending moment.

$$
M=W_{z} \cdot E \cdot \varepsilon
$$

Where: $W z$ model pile cross-section bending coefficient, $E$ is the elastic modulus of the model pile, $\varepsilon$ is pile strain.

Different slip displacement and pile spacing, pile bending moment distribution curve shown in Figure 3 to 5 .

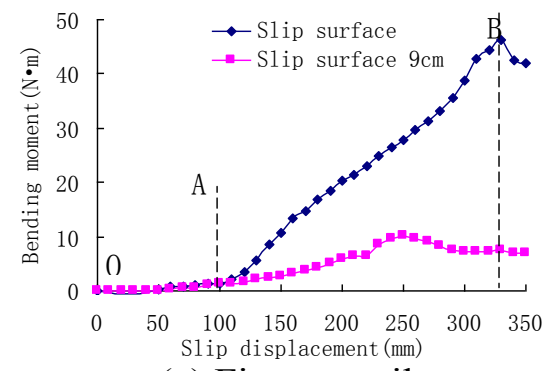

(a) First row pile

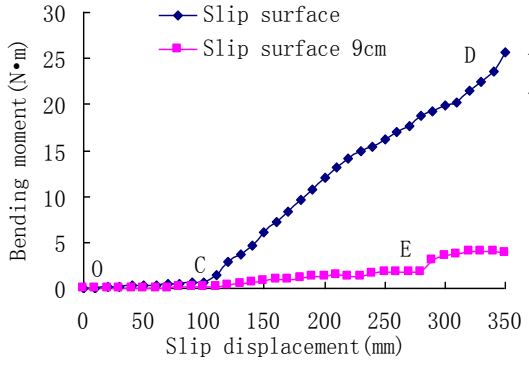

(b) Second row pile

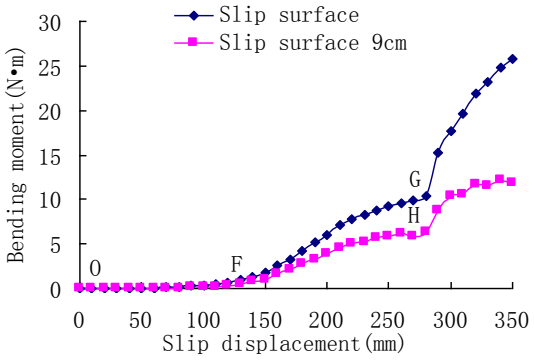

(c) Third row pile

Fig.3 Continued Sliding Conditions under Pile Bending Moment Diagram for Pile Spacing 4D

Pile spacing of 4D, when $S \leq 100 \mathrm{~mm}$, micro pile structure did not produce displacement, the bending moment of the piles is zero. Along with the continuous sliding of the sliding body, thrust in the first row of piles on the larger, pile bending deformation obviously, the bending moment of piles increased. When $S$ $=110 \mathrm{~mm}$, the thrust began to transfer to the second rows of piles, the pile bending moment curve appeared inflection point $\mathrm{C}$, the slope of the curve on the third row pile bending moment remains unchanged. When $S=280 \mathrm{~mm}$, the third row pile bending moment curve appeared inflection point $\mathrm{G}, \mathrm{H}$, indicates that the row of soil arch between piles to achieve the best transmission force state, three rows of piles started together bear the action of thrust. When $S=300 \mathrm{~mm}$, the first row of bending moment of pile reaches its limit of anti slide pile body state, gradually withdraw from the anti sliding state, shall be borne by the second and third row pile thrust.

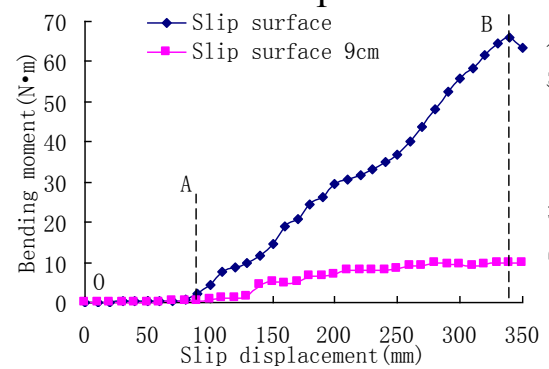

(a) First row pile

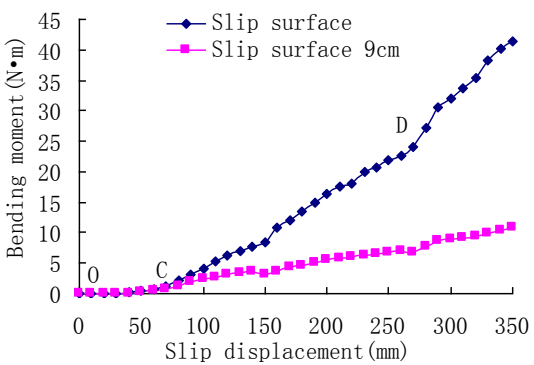

(b) Second row pile

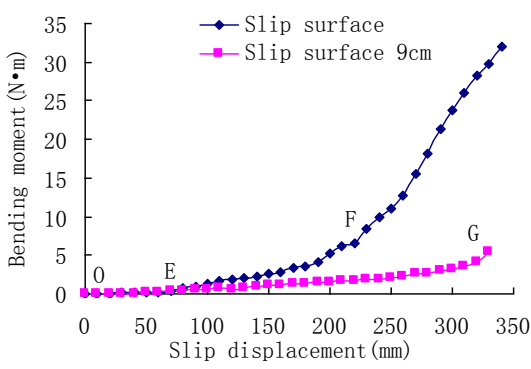

(c) Third row pile

Fig.4 Continued Sliding Conditions under Pile Bending Moment Diagram for Pile Spacing 5D

Pile spacing of 5D, when $S<100 \mathrm{~mm}$, the horizontal thrust is mainly used for extrusion compacting the landslide soil (OA), each row of pile bending moment for zero. When $S=90 \mathrm{~mm}$, the row pile bending moment curve appeared inflection point A, C, E, the bending deformation of the pile body is obvious. Along with the continuous sliding of the sliding body, the pile row and the arching effect behind piles reinforced, landslide thrust good transfer in each row of piles, pile bending moment of rapid growth. When $S=220 \mathrm{~mm}$, third rows of piles appeared inflection point $\mathrm{F}$, the bending moment of the piles of accelerated growth, that is transferred to the third rows of landslide thrust on piles is increased, the cracks in front of slope pile. When $S=250 \mathrm{~mm}$, the first row of piles earth arch reaches the limit state, the surge of the bending moment of the piles, the first row of piles in the elastic plastic deformation stage, the pile 
internal cracks began to appear, bending stiffness began to decline, the sliding body in front of crack number is increased, and the crack width increased. When $S=270 \mathrm{~mm}$, second rows of piles appear inflection point $\mathrm{D}$, shows that the most common landslide thrust began borne by the second, three rows of piles, then the third row pile bending moment curve slope is steep, the bending moment of the piles increase greatly. When $S=340 \mathrm{~mm}$, the first row anti slide pile reaches the maximum bending moment of pile body, the number of internal cracks increased, the first row of pile failure.

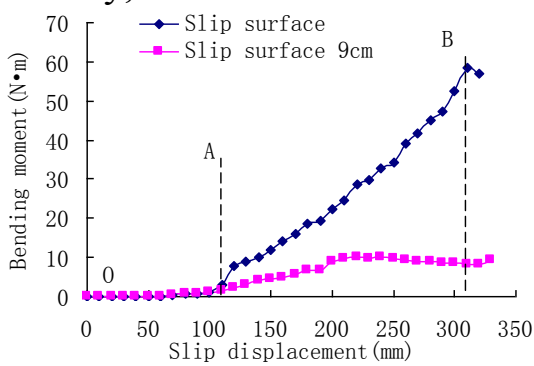

(a) First row pile

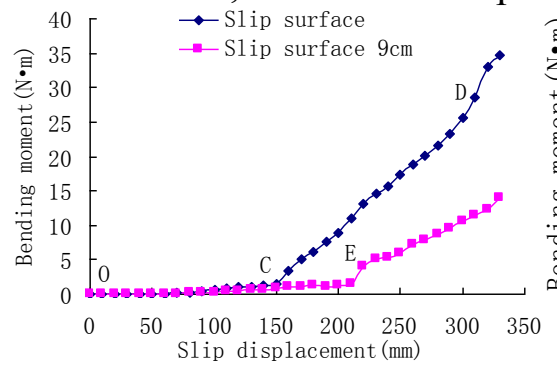

(b) Second row pile

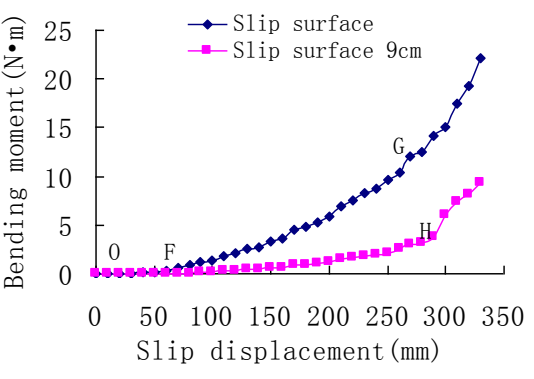

(c) Third row pile

Fig.5 Continued Sliding Conditions under Pile Bending Moment Diagram for Pile Spacing 6D

Pile spacing of $6 \mathrm{D}, \mathrm{OA}$ section pile bending moment is zero. Along with the continuous sliding of the sliding body, the first row of mini pile into plasticity stage $(\mathrm{AB})$, the bending deformation and bending moment of pile body increased, through the pile row soil arch transfer to second, three row pile thrust increased. When the third row pile bending moment curve appered inflection point $G, H$, three rows of piles started the whole force, similar anti slide retaining wall. When $\mathrm{S}=310 \mathrm{~mm}$, the first row of the bending moment of the piles to the ultimate state of anti slide pile body, gradually withdraw from the anti sliding state, shall be borne by the second and third row pile thrust, the bending moment of pile.

\section{The Landslide Thrust Transfer Coefficient}

Due to the small size of model, can not consider the effect of frictional resistance, while ignoring the pile row and in front of the pile soil resistance effect, micro pile structure independent arrangement can be simplified as the cantilever pile structure, at this point, before each pile failure, they assume the landslide thrust of the ratio of the consistent with their respective maximum bending strain ratio of pile.

According to the test results, the slide is over $100 \mathrm{~mm}$, the pile body to generate bending deformation, therefore, using $\mathrm{S}>100 \mathrm{~mm}$ after each row of piles in the bending strain elastic stage of the value distribution of landslide thrust transfer coefficient analysis. Let $\varsigma=\frac{\text { The second row pile strain }}{\text { The first row pile strain }}$, $\xi=\frac{\text { The third row pile strain }}{\text { The first row pile strain }}$, landslide thrust transfer coefficient distribution as shown in Figure 6 .

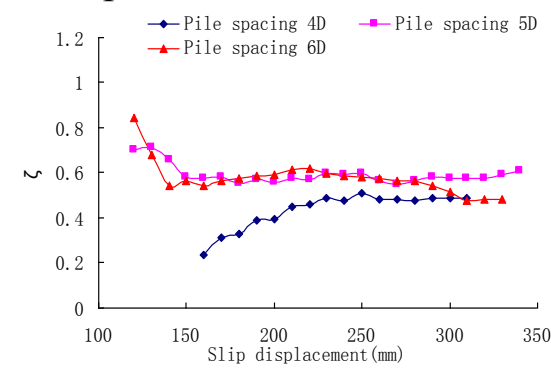

(a) $s$ curve

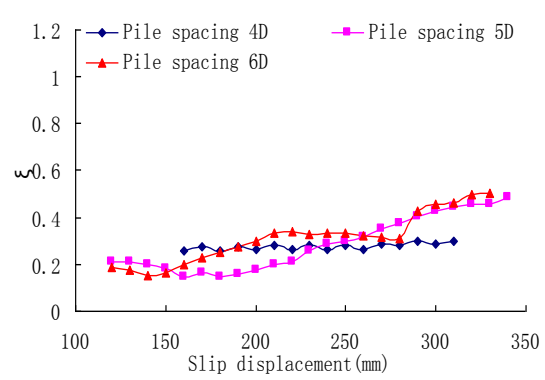

(b) $\xi$ curve

Fig.6 The Landslide Thrust Transfer Coefficient Distribution Curve

The layout of the three rows of independent micro pile structure, pile row distance phase at the same time, the pile spacing is $4 \mathrm{D}, 5 \mathrm{D}, 6 \mathrm{D}$ corresponding value $\varsigma$ in $(0.23,0.23),(0.54,0.54)$ and $(0.47,0.47)$ between the values of $\xi$ in $(0.25,0.25),(0.27,0.27)$ and $(0.21,0.21)$ between values, show that the pile 
spacing is $5 \mathrm{D}$, three rows of piles of overall mechanical performance is the best,the landslide thrust on piles in row better transfer.

\section{Conclusion}

Different pile spacing three rows of micro-piles reinforced slope engineering test, micro-pile cling mechanism following understanding:

(1) Independent arrangement of the three rows of micro pile, the pile spacing of 5D, micro pile structure can produce sliding resistance of the biggest and the maximum sliding resistance, the pile spacing is $4 \mathrm{D}$, the weakest of anti sliding ability.

(2) Pile been pressure and the bending moment of the piles mainly concentrated distribution within the scope of the sliding surface above $1 / 3$ pile range and closer to the surface greater.

(3) The micro structure of anti slide pile optimum spacing, landslide thrust transfer coefficient $\varsigma$ and $\xi$ respectively in $(0.54,0.71)$ and $(0.27,0.49)$ between the value.

\section{Acknowledgement}

This research is supported by National high technology research and development program ("863" Project) project (2012AA121302) and CCCC scientific and technological research and development project "Highway Engineering anti, mitigation key technologies"(2011-ZJKJ-04).

Author and Corresponding author: Qiang Cai(1982-), male, PhD. Mainly engaged in geotechnical dynamic process and disaster prevention.

\section{References}

[1]Wang Gong-xian. Present situation of engineering measures for preventing and controlling landslide in China and Abroad[J]. The Chinese Journal of Geological Hazard and Control.1998,9(1):1-9

[2]Kong Jiming. The Model Test Research of Breakdown Process of Layue Landslide on the Highway From Sichuan to Tibet[J]. Journal of Mountain Science. Vol. 21, Supplement pp 133-138.

[3]Yan Jinkai, Yin Yueping,Men Yuming et al. Model test study of landslide reinforcement with micropile groups China Civil Engineering Journal,201 1,44 (4):120-128

[4] Wang Shi-chuan, Chen Li-xin,Zhang Jin. The analysis of elastic-plastic design theory of anti-slidepiles(II)[J]. Journal of Xi'an University of Architecture \& Technology 1997, 29(4):426-429

[5]CHENG Yong-gang.Current situation and developments of landslide study in China in recent twenty years[J]. Journal of Geological Hazards and Environment Preservation. 2003,14(4):1-5

[6]GONG Jian, CHEN Renpeng, CHEN Yunmin, et al. Prototype testing study on micropiles under lateral loading $[\mathrm{J}]$. Chinese Journal of Rock Mechanics and Engineering, 2004, 23(20): 3 541-3 546.(in Chinese)

[7] CHEN Xichang,SHI Shengwei. Theoretical research and application prospect of composite pile with small caliber borehole[J]. The Chinese Journal of Geological Hazard and Control,2002, 13(3): 82-85.(in Chinese)

[8] Chen L, Poulos H G.Analysis of pile-soil interaction under lateral loading using infinite and finite elements[J]. Computers and Ceotechnics, 1993, 15 (4): 189-220

[9]Lee C Y, Hull T S,Poulos H G.Simplified pile-slope stability analysis[J]. Computers and Geotechnics, 1995, 17 (1):1-16

[10]Cantoni R., Collotta T, Ghionna V N, et al..A design method for reticulated micropiles structure in sliding slopes[J]. Ground Engineering, 1989, 22(1):41-47. 